\title{
QUADRO JURÍDICO DE APOIO AOS PEQUENOS EMPREENDIMENTOS: LEI DO MEI, LIMITAÇÕES E POTENCIALIDADES
}

\author{
Lucas José Campanha ${ }^{1}$ \\ Ricardo Augusto Bonotto Barboza ${ }^{2}$
}

Resumo: O objetivo foi construir arcabouço teórico sustentador para a análise do processo de implementação de uma política de formalização de microempreendedores. Apresenta-se, uma análise da evolução do instrumento jurídico. Em termos metodológicos, a pesquisa foi apoiada em pesquisa documental, via análise de conteúdo. Contatou-se que houve uma movimentação do estado brasileiro para disciplinar e garantir direitos isonômicos aos pequenos empreendimentos e que, este processo histórico e gradual, a pesar das limitações, apresenta inúmeras vantagens cujos impactos atuam na esfera individual de cada empreendimento e na esfera social, ampliando a atuação do estado e promovendo o bem-estar da população.

Palavras-chaves: Política Pública; Normas jurídicas; Empreendedorismo; Formalização; MEI.

\section{LEGAL FRAMEWORK FOR SUPPORTING SMALL ENTERPRISES: MEI LAW, LIMITATIONS AND POTENTIALITY}

\begin{abstract}
The objective was to build a supportive theoretical framework for the analysis of the process of implementation of a micro entrepreneurs formalization policy, through an analysis of the legal instrument. In methodological terms, the research was supported by documentary research. It was found that there was a movement of the Brazilian state to discipline and guarantee isonomic rights to small enterprises and that, this historical and gradual process, despite the limitations, has numerous advantages whose impacts act on the individual sphere of each enterprise and the social sphere, expanding the state's performance and promoting the welfare of the population.
\end{abstract}

Keywords: Public Policy; Legal norms; Entrepreneurship; Formalization; MEI.

\section{INTRODUÇÃO}

Indica-se que a diversidade e o pluralismo de normas, valores e crenças que caracterizam muitas sociedades criam contextos em que as instituições formais podem estar simultaneamente em conflito com os valores e crenças de diversos grupos sociais. Estes grupos sociais julgam a formalização como algo injusto e consideram as instituições formais indignas de confiança e/ou incompetentes. Por tais motivos, estes grupos sociais atuam na

\footnotetext{
${ }^{1}$ Doutorando. Programa de Pós Graduação em Desenvolvimento Territorial e Meio Ambiente. Universidade de Araraquara. lucascampanha@msn.com. Avenida Sebastião Lacerda Corrêa, 1410, Ap 81, Carmo, Araraquara-SP

${ }^{2}$ Professor Doutor. Programa de Mestrado em Direito. Universidade de Araraquara. rbonotto@ uniara.com.br.
} 
informalidade (WEBB; IRELAND; KETCHEN, 2014). As instituições informais incluem as normas, valores e crenças que moldam noções de aceitabilidade social e também podem fornecer algumas estruturas localizadas para apoiar a atividade econômica (WEBB; IRELAND; KETCHEN, 2014). O objetivo deste artigo é construir um arcabouço teórico sustentador para a análise do processo de implementação de uma política brasileira de estímulo à formalização de microempreendedores. Para tanto, foi organizado em 4 subseções: conceituou-se política pública, empreendedorismo e formalização, e apresentou-se o papel do Estado frente às questões da informalidade e empreendedorismo e a análise do instrumento jurídico de apoio. Em termos metodológicos, salienta-se que a pesquisa foi apoiada em pesquisa documental, via análise de conteúdo para avaliar a evolução do quadro legislativo.

\section{A INFORMALIDADE}

Acentua-se que apesar de toda a atenção que o setor informal tem atraído na literatura, empiricamente a própria definição do que é formal e informal está longe de ser resolvida (ELGIN, 2013; AMIN; ISLAM, 2015; WILLIAMS; NADIN, 2012; ORSI; RAGGI; TURINO, 2014; LOUREIRO; ARAUJO; SOUZA, 2013). Para alguns, empresas informais são definidas como aquelas que não apresentam registro junto às autoridades competentes (GINDLING; TERRELL, 2005; LOAYZA; RIGOLINI, 2011, MEAD; MORRISSON, 1996; RAND; TORM, 2012; AMIN; ISLAM, 2015). Para outros a economia informal é compreendida como a produção e/ou venda de bens lícitos cuja remuneração não é declarada às autoridades tributárias, de segurança social e/ou de trabalho, quando deveria ser declarada (WILLIAMS; NADIN, 2012). Por fim, delimita-se que informalização pode ser definida como um processo caracterizado por um aumento no tamanho das atividades e da geração de renda que ocorre fora do âmbito do Estado (KUS, 2014).

Segundo Webb e colaboradores $(2009$; 2013) a economia informal refere-se ao conjunto de atividades legítimas e ao conjunto de atividades ilegais através das quais os atores reconhecem e exploram oportunidades empreendedoras. As atividades são consideradas legais se elas são definidas e reguladas pelas instituições formais, incluindo leis e regulamentos. Dentro deste parâmetro, as atividades da economia informal são ilegais porque elas ocorrem fora das instituições formais. No tocante à legitimidade, Lee e Shih-Chang (2014) acentuam que os produtos, métodos e práticas do setor informal são aceitos por certos grupos sociais. Infere-se assim que a legitimidade é fundamental para as atividades da economia informal. 
Legitimidade é uma percepção generalizada ou suposição de que as ações de uma entidade são desejáveis, apropriadas, ou adequadas dentro de um sistema socialmente construído de normas, valores, crenças e definições (SUCHMAN, 1995). Empreendedores informais procuram normalmente três formas de legitimidade: pragmática, moral e cognitiva, de forma que: a) Legitimidade pragmática reflete julgamentos sobre os benefícios proporcionados por uma determinada atividade informal em um determinado grupo; b) Legitimidade moral reflete uma avaliação normativa positiva do empreendedor informal e de suas atividades; e c) Legitimidade cognitiva aumenta a compreensão do público e, finalmente, normatiza atividades que antes eram consideradas ilegítimas (LEE; SHIH-CHANG HUNG, 2014). Em suma, tem-se no quadro 1, as principais definições para informalidade.

Quadro 1 - Definições de informalidade

\begin{tabular}{|lll|}
\hline Autor & \multicolumn{1}{c|}{ Conceito } \\
\hline $\begin{array}{l}\text { Gindling e Terrell (2005); } \\
\text { Loayza, Rigolini e (2011); Mead }\end{array}$ & $\begin{array}{l}\text { Aquelas que não apresentam registro junto às autoridades } \\
\text { competentes }\end{array}$ \\
$\begin{array}{l}\text { e Morrisson (1996); Rand e } \\
\text { Torm (2012); Amin e Islam } \\
(2015)\end{array}$ & \\
\hline Williams e Nadin (2012) & $\begin{array}{l}\text { A produção e / ou venda de bens lícitos cuja remuneração } \\
\text { não é declarada às autoridades tributárias, de segurança } \\
\text { social e / ou de trabalho }\end{array}$ \\
\hline Kus (2014) & $\begin{array}{l}\text { Um processo caracterizado por um aumento no tamanho } \\
\text { das atividades e da geração de renda que ocorre fora do } \\
\text { ambito do estado }\end{array}$ \\
\hline $\begin{array}{l}\text { Webb e colaboradores } \\
2013)\end{array}$ & $\begin{array}{l}\text { Conjunto de atividades legítimas porém ilegais através } \\
\text { das quais os atores reconhecem e exploram oportunidades } \\
\text { empreendedoras }\end{array}$ \\
\hline
\end{tabular}

Fonte: Elaboração própria (2019)

Sugere-se que a noção da economia informal foi introduzida no início dos anos 1970 para explicar as principais atividades não regulamentadas (ainda que fossem bem organizados) das sociedades pobres. Contudo, e certo que as atividades econômicas informais foram iniciadas muito antes da década de 1970, podendo-se mesmo dizer que existem desde sempre.

Acemoglu e Robinson (2012) fornecem numerosos casos de empreendedorismo que poderiam ser considerados de natureza informal. Por exemplo, no século XIV na China, o Imperador Hongwu executou centenas de empresários a fim de concentrar o comércio internacional nas atividades governamentais. Na Inglaterra, durante os anos de 1500 e 1600, a 
rainha Elizabeth e mais tarde o rei James I se recusaram a permitir William Lee de comercializar o seu quadro de lotação (também conhecido por mecanização da produção têxtil) dado o receio de que esta inovação suplantaria o trabalho humano, criando desemprego e instabilidade política. Na Áustria-Hungria durante o século XIX, os Habsburgos proibiram a difusão de novas tecnologias, tais como estradas de ferro e motor a vapor, que poderiam levar à destruição criativa e alterar a posição das elites tradicionais. Outro exemplo citado é o ocorrido durante as décadas de 1920 e 1930, quando foi implementada a Lei Seca nos Estados Unidos e, como resposta, proliferaram-se bares clandestinos e o contrabando foi organizado (ACEMOGLU; ROBINSON, 2012).

Estas diversas atividades mostram que, ao longo da história, os empresários têm procurado quebrar ou alterar as regras institucionais formais. Enquanto as atividades descritas anteriormente tinham o potencial para criar valor significativo para a sociedade, abordando as necessidades do mercado insatisfeito e aumentando da produtividade, eles foram rejeitados por instituições formais, devido aos custos sociais reais ou imaginários (WEBB; IRELAND; KETCHEN, 2014).

Atualmente o empreendedorismo informal representa um fenômeno complexo (AGUILAR-BARCELÓ; TEXIS-FLORES; RAMÍREZ-ANGULO, 2011; UZO; JOHANNA MAIR, 2014) que se materializa como um dos principais desafios na luta contra a pobreza (BAUWENS; LEMAITRE, 2014). O segmento informal é de suma importância para a economia. Ele apresenta-se em um tamanho maior em economias em desenvolvimento, particularmente na África e na América Latina (UZO; JOHANNA MAIR, 2014; AMIN; ISLAM, 2015; WILLIAMS; NADIN; 2012).

As economias em desenvolvimento são caracterizadas por vazios institucionais; geralmente são economias que estão associadas com um campo do Direito pouco definido, principalmente nas questões relacionadas à propriedade, aos contratos e à corrupção desenfreada. Frequentemente apresentam serviços públicos pouco efetivos, dispõem de acesso limitado às infraestruturas de transporte e de comunicação, e possuem sistemas jurídicos e aparelhos de execução ineficientes (WEBB; IRELAND; KETCHEN, 2014).

Neste contexto, a demarcação da legalidade torna-se turva, mesmo quando as leis são claramente formalizadas, os aparatos de execução são, muitas vezes, ineficientes e corruptos, o que estimula a informalidade. Portanto, o significado das leis torna-se ambíguo, da mesma forma, a aplicação é inconsistente. Além disso, o cumprimento das leis gera custos e o efeito 
desses custos é amplificado dentro dessas configurações o que eleva os custos da formalização (WEBB; IRELAND; KETCHEN, 2014).

Kus (2014) reconhece que existe uma extensa literatura sobre as causas da informalização, porém, três vertentes de pensamento se destacam, tal como apresentado na figura 1 .

Figura 1 - Causas da informalidade

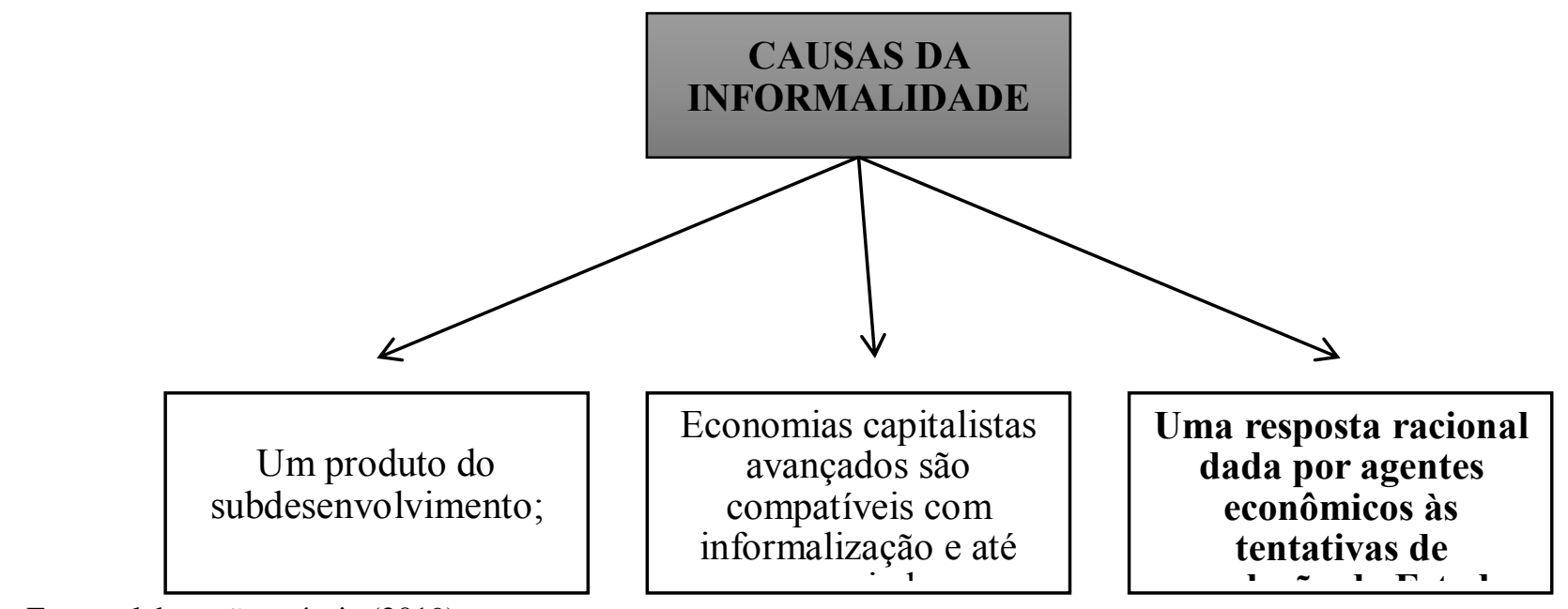

Fonte: elaboração própria (2019)

Neste sentido, esclarece-se que:

- A primeira visão surgiu a partir da primeira onda de pesquisa, que foi realizada em grande parte na África. Esta vertente caracteriza as atividades informais como um produto do subdesenvolvimento. Com base nesta perspectiva, o aumento do desenvolvimento da economia de um país, por meio de atividades capitalistas expandidas e da industrialização, levará a uma maior formalização da atividade econômica;

- A segunda linha de pensamento rejeita a conexão de informalização ao subdesenvolvimento econômico. Em vez disso, ela afirma que as estruturas que acompanham as economias capitalistas avançados são compatíveis com informalização e até mesmo ajudam a promovê-la. Os defensores dessa linha de pensamento afirmam que, fornecendo às empresas oportunidades de produção mais flexível com geração de lucro e redução de custos, amplia-se o índice de formalização;

- A terceira e última linha de pensamento sobre a atividade econômica informal retrata a informalidade como uma resposta racional dada por agentes econômicos às tentativas 
de regulação do Estado. Este ponto de vista afirma que os agentes econômicos recorrem à informalidade em situações em que os custos elevados à entrada no mercado formal são impostos pelo Estado, muitas vezes através de exigências onerosas de registro, taxas de licenciamento, impostos altos, ou trabalho rigoroso e regulamentos ambientais (KUS,2014).

Este trabalho vai ao encontro da terceira vertente. Portanto, defende-se que o fenômeno da informalidade pode se manifestar quando empreendedores formais concluem que as leis são demasiadamente restritivas, levando-os a exercerem atividades nas economias informais como uma oportunidade, fazendo uma escolha racional em termos da formalização (CASTRO; KHAVUL; BRUTON, 2014; WEBB; IRELAND; KETCHEN, 2014; DE MEL; CKENZIE; WOODRUFF, 2013; LOUREIRO; ARAUJO; SOUZA, 2013).

Evidenciando o aspecto racional como motivador da informalidade, os estudos de De Mel, Ckenzie e Woodruff (2013) e Castro, Khavul e Bruton (2014) evidenciam que os empreendedores informais do Siri Lanka e da República Dominicana permanecem informais não por causa de barreiras à entrada de formalização, mas porque a formalização não faz sentido econômico em termos do que eles recebem em troca de suas contribuições fiscais. Outra evidência da informalização como escolha racional é percebida em Maloney (2004), para quem microempresas informais urbanas da América Latina podem ser classificadas como agentes que, em nome da falta de fiscalização, optam pelo grau de atividade formal que pretendem produzir.

Elgin (2013) e Elgin e Uras (2013) argumentam que o aumento na taxa de imposto leva à redução da informalidade à medida que o imposto é uma força motriz do Estado na efetivação de políticas públicas capazes de impulsionar a economia, eles salientam, porém, que países com elevada corrupção alteram este quadro, pois os empreendedores se sentem injustiçados e a elevação de imposto induz ainda mais a informalidade. Desta forma, políticas eficientes para a redução da informalidade devem pautar-se também, na redução da corrupção.

Ratifica-se que o setor informal é altamente heterogêneo (AMIN; ISLAM, 2015; WILLIAMS; NADIN; 2012; UZO; JOHANNA MAIR, 2014; GRIMM; KNORRINGA; LAY, 2012). Para alguns, os empreendedores informais são orientados por necessidade, ou seja, formam um empreendedorismo caracterizado por adjetivos tais como "involuntário", "forçado", "relutante" ou "de sobrevivência" (BOYLE, 1994; SINGH; DE NOBLE, 2003; 
HORMIGA; BATISTA-CANINO; SA'NCHEZ-MEDINA, 2011; BOYLE, 1994; SASSEN, 1997; GALLIN 2001; WILLIAMS; NADIN, 2012).

Para outros, o empreendedorismo informal é uma opção, uma oportunidade de seguir uma nova carreira, um novo caminho, de transformar o trabalho e/ou revelar o verdadeiro eu (CROSS, 1997; GERXHANI; 2004; MALONEY, 2004; WILLIAMS; NADIN; 2012). Desta forma, alguns optam pela informalidade por falta de opção, ou seja, são indivíduos que não conseguem emprego em outras atividades sendo empreendedores informais por necessidade (CUNNINGHAM; MALONEY, 2001, DE MEL; CKENZIE; WOODRUFF, 2010; MALONEY, 2004). Outros veem a informalidade como um trampolim e estão no setor por opção (CUNNINGHAM; MALONEY, 2001; DE MEL; CKENZIE; WOODRUFF, 2010; MALONEY, 2004). Indica-se, que um grupo de empreendedores informais está buscando a formalização enquanto outro não tem este objetivo (WILLIAMS; NADIN; 2012).

Outra característica da heterogeneidade do setor informal é apontada por Grimm, Knorringa e Lay (2012). Ao estudar sete países da África Ocidental os autores identificaram 3 perfis de empresários, tipificados a partir do tamanho da empresa e do acesso ao capital:

- Em um primeiro grupo estão os empreendedores orientados por oportunidades e que buscam o crescimento. Este grupo apresenta elevados níveis de habilidades gerenciais, elevado capital e bom desempenho;

- Em um segundo grupo está os empreendedores orientados pela necessidade e pela busca de sobrevivência, com baixos níveis de capital e que estão à espera de melhores oportunidades de emprego;

- Um terceiro grupo é aquele formado por empreendedores com características próximas ao primeiro grupo, que operam, porém com os estoques de capital substancialmente mais baixo (GRIMM; KNORRINGA; LAY, 2012).

Castro, Khavul e Bruton (2014), Webb, Ireland e Ketchen (2014) e Lin et al. (2015) sugerem que as empresas podem escolher os níveis de conformidade que irão adotar para atender algumas das expectativas do seu ambiente institucional macro sem violar às normas e práticas de seu ambiente cultural. Os autores entendem que a informalidade é um continuum multidimensional que varia de nenhum registro formal com qualquer agência do governo para graus de registro parcial com as autoridades intermédias e entre várias dimensões 
institucionais. Contribuindo, Webb, Ireland e Ketchen (2014) acentuam que o empreendedor pode ser informal ao adotar atividades diversas, tais como:

- O contorno de regulamentos gerais de negócios: corresponde às decisões dos empresários em não registrar seus negócios, obter as licenças apropriadas para o seu tipo específico de negócio, e/ou ignorar requisitos específicos para operar dentro de uma indústria específica;

- O contorno das leis fiscais: neste caso, os empresários evitam o pagamento de impostos, segurança social, e outros desembolsos necessários, ações facilitadas por transações em dinheiro; falta de registro e outras decisões criativas de contabilidade;

- O contorno das leis de direitos de propriedade: diz respeito aos produtos falsificados e lojas que comercializam a pirataria de software e os serviços que facilitam a venda não aprovada;

- O contorno das leis trabalhistas: correspondem à utilização de trabalhadores em situação irregular, condições de exploração, a utilização de trabalho infantil e a desconsideração do salário mínimo e dos requisitos máximos de horas trabalhadas;

- O contorno de regulamentos ambientais: corresponde ao uso de produtos químicos e combustíveis proibidos, excedendo aos limites de poluição especificados, desconsiderando as limitações sobre o comércio de animais exóticos, a regulamentação da pesca e da destruição das florestas;

- O contorno de outras leis e regulamentos (por exemplo, leis de importação e os regulamentos da Internet): diz respeito, por exemplo, à importação de produtos farmacêuticos que não receberam aprovação regulatória no mercado interno, mas receberam aprovação internacional; ou a importação de automóveis que não seguem as normas de um país em termos de limitações de segurança ou de escape.

Entende-se que parcela das atividades postuladas por Webb, Ireland e Ketchen (2014) é, na verdade, atividades executadas na ilegalidade e na informalidade. Um exemplo clássico é a pirataria e o trabalho infantil. Tendo em vista estas ponderações, outra classificação possível para os empreendedores informais é apresentada por Willians e Nandin (2012). Estes autores classificam os empreendedores informais em quatro categorias:

- Empreendedores que atuam totalmente na informalidade: 
1. Operacionais não registrados, ou seja, empresas fantasmas permanentemente compostas por empreendedores que atuam inteiramente na economia informal, e que não apresentam a intenção de se formalizar no futuro previsível;

2. Empreendedoras que atuam totalmente na informalidade, no entanto apresentam a intenção de se formalizar num futuro próximo, ou seja, criam empresas 'fantasmas temporárias';

- Empreendedores que atual parcialmente na informalidade:

3. Empreendedores formalizados com contribuições e pagamentos de impostos ativos, porém com uma parcela da renda não declarada e sem intenção de aumentar a quota declarada;

4. Empreendedores formalizados com contribuições e pagamentos de impostos ativos, com uma parcela da renda não declarada e com a intenção de aumentar a quota declarada (WILLIAMS; NADIN; 2012).

Em síntese, percebe-se que a informalidade não é um conceito absolto, o empreendedorismo pode atuar em diversas escalas de formalização. Em muitas sociedades o fator cultural é aquele com maior preponderância sobre a decisão de se formalizar ou não. Percebe-se ainda que muitas destas variáveis presentam um efeito cascata, onde uma acaba levando à incidência da outra. Conhecer estas variáveis e o efeito cascata de cada um destes fatores é um ponto crítico ao sucesso de toda e qualquer política que o Estado deseja implementar para alterar o quadro da informalidade em seu território. Na próxima seção, é realizada uma breve contextualização em torno do termo políticas públicas e do aparato legal pensado para o caso brasileiro de apoio à formalização

\section{O ESTADO BRASILEIRO FRENTE À QUESTÃO DO EMPREENDEDORISMO E DA INFORMALIDADE}

O esforço de estruturar políticas públicas para PME no Brasil é recente. O descaso esteve presente ao longo da história, seja nos períodos de substituição de industrialização e substituição das importações das décadas de 1950 a 1970, passando pela crise econômica da década de 1980 até o período de neoliberalismo econômico da primeira metade da década de 1990 (SARFATI, 2013). Apenas no período recente, empresas desse porte passaram a receber maior atenção (SARFATI, 2013; NARETTO; BOTELHO; MENDONÇA, 2014). 
Sarfati (2013) pondera que as políticas públicas de estímulo ao empreendedorismo (com especial ênfase às MPE) devem ser pautadas e fundamentadas nos condicionantes da atividade empreendedora tais como: mudanças demográficas - movimentos migratórios, idade, etc; mudanças sociais, consciência ambiental, nível de educação, etc; mudanças econômicas - estabilidade macroeconômica, relações comerciais com outros países, etc; mudanças regulatórias - oportunidades advindas em mudanças de regulação em setores específicos incluindo regulações definidas em contextos multilaterais; mudanças tecnológicas - emergência de novas tecnologias. Essas políticas podem ser classificadas em políticas regulatórias e políticas de estímulo (SARFATI, 2013).

As políticas regulatórias que afetam as Micros, Pequenas e Médias Empresas MPME e o empreendedorismo são aquelas que definem as regras de entrada e saída de negócios; as regras trabalhistas e sociais; as regras de propriedade; as regras tributárias; as regras de propriedade intelectual; as regras de falência; e as regras que afetem a liquidez e disponibilidade de capital (incluindo taxas de juro e acesso a financiamento) (SARFATI, 2013).

Neste contexto, as políticas regulatórias de estímulo ao empreendedorismo no Brasil se iniciaram pela Constituição Federal. No artigo 170 há explicitada a indicação de "dar tratamento favorecido para as empresas brasileiras de capital nacional de pequeno porte" (BRASIL, 1988). No art. 179 tem-se, novamente, a previsão do tratamento diferenciado.

A União, os Estados, o Distrito Federal e os Municípios dispensarão às microempresas e às empresas de pequeno porte, assim definidas em lei, tratamento jurídico diferenciado, visando a incentivá-las pela simplificação de suas obrigações administrativas, tributárias, previdenciárias e creditícias, ou pela eliminação ou redução destas por meio de lei (BRASIL, 1998).

O Decreto-Lei $\mathrm{n}^{\circ} 486 / 1969$ apresentou tratamento diferenciado para o pequeno comerciante, onde o dispensa da realização da escrituração obrigatória (BRASIL, 1969). Avançando ainda mais na democratização da formalização, tem-se a Lei no 9.317/96 que instituiu o Sistema Integrado de Pagamento de Impostos e Contribuições (Lei do SIMPLES). Essa Lei procurou estimular e reduzir o número de impostos, racionalizando a sua cobrança e dispensando a escrituração contábil para fins fiscais, objetivando legalizar as micro e pequenas empresas.

Os impactos produzidos pela lei 9.317/96 fizeram-se sentir também na reformulação do código civil, já que com a promulgação da Lei no 10.406/ 2002 (novo código civil) observou-se uma reformulação no conceito de empresário que passou a ser considerado como 
aquele que: "exerce profissionalmente atividade econômica organizada para a produção ou a circulação de bens ou de serviços" (BRASIL, 2002). Além do mais, o novo código civil assegurou tratamento favorecido, diferenciado e simplificado ao empresário rural e ao pequeno empresário que queira fazer a inscrição como pessoa jurídica. Observa-se, neste momento, que a figura do empresário sofreu mudanças, antes só eram considerados empresários aqueles que praticavam o comércio (OLIVEIRA, 2012). Novamente, em 2003, a Emenda Constitucional $n^{\circ} 42 / 2003$ desonerou o processo de legalização das pequenas empresas, alterando o Sistema Tributário Nacional e dispensando tratamento diferenciado e favorecido para as microempresas e para as empresas de pequeno porte.

Indica-se que a lei do Simples foi revogada em sua totalidade em 2006. Em seu lugar passou a vigorar a Lei Complementar $\mathrm{n}^{\circ}$ 123, de 14 de dezembro de 2006, denominada de Lei Geral das Micro e Pequenas Empresas, que instituiu o Estatuto Nacional da Microempresa e da Empresa de Pequeno Porte (Simples Nacional), promovendo uma simplificação na arrecadação de impostos, principalmente para Microempresas (ME) e Empresas de Pequeno Porte (EPP) e individualizou as pequenas e micro empresas pela mensuração de suas receitas brutas anuais, esta lei representou a primeira postura oficial do Governo para reduzir o quadro de incertezas e para combater a informalidade no país (BRASIL, 2006).

Novos avanços foram proporcionados pela Lei $\mathrm{n}^{\mathrm{o}} 11.598 / 2007$, que criou a Rede Nacional para a Simplificação do Registro e da Legalização de Empresas e Negócios REDESIM e estabelece normas gerais para a simplificação e integração do processo de registro e legalização de empresários e de pessoas jurídicas.

Observa-se ainda que a postura de apoio aos micro e pequenos empreendimentos foi

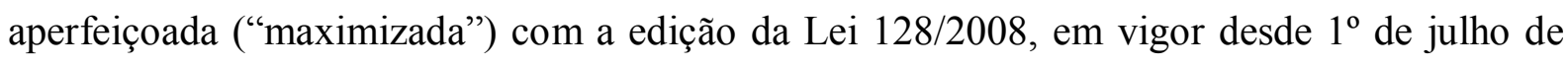
2009, que alterou a Lei Geral das Micro e Pequenas Empresas, para instituir no cenário jurídico a figura do Microempreendedor Individual (MEI). Tem-se também a Lei n. 12.470, de 31 de agosto de 2011 que reduziu a carga tributária do MEI, de forma que a alíquota para previdência social passou de 11\% para 5\% (BRASIL, 2011).

Outras contribuições vieram da Lei n. 12.470, de 31 de agosto de 2011 que reduziu a carga tributária do MEI, e ampliou em $50 \%$ os limites de faturamento previstos, permitindo que mais empreendedores participem do regime que simplifica o entendimento e diminui a tributação. No arcabouço jurídico novos direitos foram proporcionados em 2014 pela Lei 
Complementar $n^{\circ} 147$, que alterou a Lei Complementar $n^{\circ} 123 / 2006$, com simplificação de processos e procedimentos, impediu o aumento de IPTU, cobranças de taxas diversas e normatizou o processo de cobranças de taxas associativas para o MEI, bem como modifica partes da Lei Geral da Micro e Pequena Empresa - Lei Complementar 123/2006. No sentido de propiciar simplificação, foi promulgado ainda, em 2016 a Lei Complementar $n^{\circ} 155$ que alterou a Lei Complementar $n^{\circ} 123$ para reorganizar e simplificar a metodologia de apuração do imposto devido por optantes pelo Simples Nacional; alterou as Leis $\mathrm{n}^{\circ}$ 9.613/98, 12.512/2011, e 7.998/90; e revoga dispositivo da Lei ${ }^{\circ}$ 8.212/91.

No que tange às políticas de estímulo, indica-se que elas estão relacionadas a ações que, diretamente, promovem a atividade empreendedora. Lastres e Lemos (2003) identificam quatro conjuntos de ações voltadas diretamente à promoção da atividade empreendedora:

- O primeiro conjunto de ações essenciais refere-se à cultura empreendedora e ao empreendedorismo. Os principais instrumentos utilizados incluem os programas de divulgação, demonstração e premiação - como o estabelecimento de datas comemorativas, a realização de feiras e torneios de empreendedorismo - e também a disponibilização de infraestrutura, logística, serviços básicos, etc. neste âmbito a ênfase tem sido conferida à constituição de incubadoras, empresas juniores, parques tecnológicos e arranjos produtivos locais;

- O segundo conjunto, referente a serviços de apoio, geralmente inclui programas de informação, capacitação e consultoria. As políticas deste conjunto vêm procurando apoiar as empresas, fortalecendo suas capacidades e competências centrais de forma continuada, dentro de uma perspectiva de longo prazo. Destaca-se a tendência à descentralização desta política via empresas do terceiro setor, assim como o estabelecimento de instituições que atuam como uma porta de entrada para a solução dos mais variados problemas das empresas. Salienta-se que atualmente a referência como centro descentralizado de apoio é o SEBRAE (Serviço Brasileiro de Apoio às Micro E Pequenas Empresas).

- O terceiro conjunto refere-se a formas de financiar a criação e o desenvolvimento de MPE, variando desde financiamentos diretos (a fundo perdido ou com retorno), incentivos fiscais e sistemas de venture capital, até destinações específicas de parcela do orçamento público e compras de governo. Estas políticas têm procurado, por um 
lado, aperfeiçoar os mecanismos existentes e diminuir os tradicionais entraves enfrentados quanto à obtenção de financiamentos.

Neste conjunto a ênfase tem sido conferida à ampliação de linhas de financiamento do Banco Nacional de Desenvolvimento Econômico e Social - BNDES; Financiadora de Estudos e Projetos - FINEP; das Fundações estaduais de Amparo à pesquisa; do Conselho Nacional de Desenvolvimento Científico e Tecnológico (CNPq); do Programa Federal de Geração de Renda (Proger); do Programa Nacional do Microcrédito Produtivo Orientado. Nestas políticas, os seguintes aspectos positivos podem ser destacados:

- A redução nos custos e diluição de riscos associados ao financiamento a empresas individuais e particularmente as de menor porte;

- A superação das tradicionais barreiras ligadas ao fornecimento de garantias e ao financiamento de médio e longo prazo;

○ O fortalecimento das relações entre atores nos arranjos e sistemas visando o aumento das sinergias coletivas e o desenvolvimento de formas interativas de aprendizado.

- Um quarto conjunto diz respeito à simplificação da burocracia. Os principais esforços visam reduzir procedimentos e prazos para facilitar a criação de novas empresas, sua atuação e seu financiamento. Um exemplo de iniciativas como esta é o Módulo Estadual de Licenciamento do Via Rápida Empresa do Estado de São Paulo. Um programa que integra os sistemas Cadastro Web e o Sistema Integrado de Licenciamento (SIL), para coleta de dados para o registro empresarial, consulta prévia da viabilidade de localização apenas para os municípios conveniados, e as licenças para o exercício das atividades econômicas, envolvendo os municípios paulistas (conveniados ou não) e os órgãos estaduais responsáveis pelo licenciamento: Vigilância Sanitária (representada pelo Centro de Vigilância Sanitária - CVS), Meio Ambiente (representado pela CETESB - Companhia Ambiental do Estado de São Paulo) e Corpo de Bombeiros.

De tudo o que foi apresentado, infere-se que as políticas públicas para PME encampam o apoio mediante criação de instituições, marco legal e normas tributárias específicas e a mobilização de mecanismos no âmbito das instituições públicas de suporte ao 
sistema produtivo - bancos oficiais, agências de fomento, institutos de pesquisa e universidades (NARETTO; BOTELHO; MENDONÇA, 2014). Nota-se também, que todas as políticas de estímulo ao empreendedorismo podem ser analisadas em diversas dimensões verticais tais como: Política nacional ou regional; focadas em setores específicos (como biotecnologia) e Grupos de indivíduos (negros, mulheres, jovens) (SARFATI, 2013).

Conclui-se que no Brasil as políticas públicas se fracionam entre diversos atores nacionais e regionais não havendo qualquer claro ponto focal dos programas. Os programas se sobrepõem entre a atuação de atores nacionais e regionais e no foco generalizado e setorial. Entretanto, especialmente desde o estabelecimento do Estatuto das Micro e Pequenas empresas e da criação da lei do MEI, observa-se mecanismos que, pela primeira vez na história do país, configurariam uma política de MPE.

\section{LEIS E DECRETOS QUE NORMATIZAM A ATUAÇÃO DO MEI}

A Lei Complementar n $n^{\text {1 }}$ 128, de 19/12/2008, criou condições especiais para que o trabalhador conhecido como informal possa se tornar um Microempreendedor Individual (MEI) legalizado. MEI é a pessoa que trabalha por conta própria e que se legaliza como pequeno empresário. Para ser um microempreendedor individual é necessário faturar no máximo até $\mathrm{R} \$ 81.000,00$ por ano e não ter participação em outra empresa como sócio ou titular. O MEI também pode ter um empregado contratado que receba o salário mínimo ou o piso da categoria.

Entre as vantagens oferecidas por essa lei está o registro no Cadastro Nacional de Pessoas Jurídicas (CNPJ), o que facilita a abertura de conta bancária, o pedido de empréstimos e a emissão de notas fiscais. Além disso, o MEI será enquadrado no Simples Nacional e ficará isento dos tributos federais (Imposto de Renda, Programa de Integração Social- PIS, Contribuição para o Financiamento da Seguridade Social - Cofins, Imposto Sobre Produtos Industrializados - IPI e Contribuição Social Sobre o Lucro Líquido - CSLL). Assim, pagará apenas o valor fixo mensal de $\mathrm{R} \$ 40,40$ (comércio ou indústria), $\mathrm{R} \$ 44,40$ (prestação de serviços) ou $\mathrm{R} \$$ 45,40 (comércio e serviços), que será destinado à Previdência Social e ao Imposto Sobre Circulação De Mercadorias E Serviços - ICMS ou ao Imposto Sobre Serviços De Qualquer Natureza -ISS. Essas quantias serão atualizadas anualmente, de acordo com o salário mínimo. Com essas contribuições, o Microempreendedor Individual tem acesso a benefícios como auxílio maternidade, auxílio doença, aposentadoria, entre outros. 
Algumas das causas que dificultavam a formalização do MEI eram, certamente, os entraves que os trabalhadores informais enfrentavam para a comprovação legal de suas atividades, tais como: comprovação de renda; falta de comprovação legal de aquisição de suas mercadorias; reclamações trabalhistas; falta de benefícios previdenciários para o próprio empreendedor, entre outras (CORDEIRO, 2012). Considerável parcela desses obstáculos foi removida com o advento da lei 128/08, que agilizou trâmites burocráticos e facilitou a administração dos empreendimentos formais recém-surgidos (CORDEIRO, 2012). Tais vantagens e desvantagens são normatizadas por arcabouço jurídico sustentador, sintetizado no quadro 2.

Quadro 2 - Leis de apoio ao MEI

\begin{tabular}{|c|c|}
\hline Lei & Definição e principais características \\
\hline Lei n ${ }^{\circ} 11.598 / 2007$ & $\begin{array}{l}\text { Cria a Rede Nacional para a Simplificação do Registro e da } \\
\text { Legalização de Empresas e Negócios - REDESIM e estabelece } \\
\text { normas gerais para a simplificação e integração do processo de } \\
\text { registro e legalização de empresários e de pessoas jurídicas. }\end{array}$ \\
\hline $\begin{array}{l}\text { Lei Complementar } \\
n^{\circ} 123 / 2006\end{array}$ & $\begin{array}{l}\text { Institui o Estatuto Nacional da Microempresa e da Empresa de } \\
\text { Pequeno Porte, também conhecido como a Lei Geral da Micro e } \\
\text { Pequena Empresa. }\end{array}$ \\
\hline $\begin{array}{l}\text { Lei Complementar } \\
\mathrm{n}^{\circ} 128 / 2008\end{array}$ & $\begin{array}{l}\text { Cria a figura do Microempreendedor Individual - MEI e modifica } \\
\text { partes da Lei Geral da Micro e Pequena Empresa - Lei } \\
\text { Complementar 123/2006. }\end{array}$ \\
\hline $\begin{array}{l}\text { Lei Complementar } \\
n^{\circ} 139 / 2011\end{array}$ & $\begin{array}{l}\text { Altera o limite de faturamento do MEI para até } \mathrm{R} \$ 60.000,00 \text { e } \\
\text { modifica partes da Lei Geral da Micro e Pequena Empresa - Lei } \\
\text { Complementar 123/2006. }\end{array}$ \\
\hline $\begin{array}{l}\text { Lei Complementar } \\
n^{\circ} 147 / 2014\end{array}$ & $\begin{array}{l}\text { Altera a Lei Complementar } \mathrm{n}^{\circ} 123 / 2006 \text {, com simplificação de } \\
\text { processos e procedimentos, impede o aumento de IPTU, cobranças } \\
\text { de taxas diversas e normatiza o processo de cobranças de taxas } \\
\text { associativas para o MEI, bem como modifica partes da Lei Geral da } \\
\text { Micro e Pequena Empresa - Lei Complementar } 123 / 2006 \text {. }\end{array}$ \\
\hline $\begin{array}{l}\text { Decreto } \mathrm{n}^{\circ} \\
6.884 / 2009\end{array}$ & $\begin{array}{l}\text { Cria o Comitê para Gestão da Rede Nacional para a Simplificação } \\
\text { do Registro e da Legalização de Empresas e Negócios - CGSIM. }\end{array}$ \\
\hline $\begin{array}{l}\text { Lei Complementar } \\
n^{\circ} 155 / 2016\end{array}$ & $\begin{array}{l}\text { Altera a Lei Complementar } \mathrm{n}^{\circ} 123 / 2006 \text {, para reorganizar e } \\
\text { simplificar a metodologia de apuração do imposto devido por } \\
\text { optantes pelo Simples Nacional; altera as Leis } \mathrm{n}^{\circ} 9.613 / 98 \text {, } \\
\text { 12.512/2011, e 7.998/90; e revoga dispositivo da Lei } \mathrm{n}^{\circ} 8.212 / 91 \text {. }\end{array}$ \\
\hline $\begin{array}{l}\text { Resolução CGSIM } \\
\text { n }^{\circ} 1 / 2009\end{array}$ & $\begin{array}{l}\text { Aprova o Regimento Interno do Comitê para Gestão da Rede } \\
\text { Nacional para Simplificação do Registro e da Legalização de } \\
\text { Empresas e Negócios. }\end{array}$ \\
\hline $\begin{array}{l}\text { Resolução CGSIM } \\
\mathrm{n}^{\circ} 18 / 2010\end{array}$ & $\begin{array}{l}\text { Estabelece as normas para transferência de dados do } \\
\text { Microempreendedor Individual - MEI às entidades que integrarm o }\end{array}$ \\
\hline
\end{tabular}




\begin{tabular}{|c|c|}
\hline & CGSIM e seus grupos de trabalho. \\
\hline $\begin{array}{l}\text { Resolução CGSIM } \\
\text { n }^{\circ} 22 / 2010\end{array}$ & $\begin{array}{l}\text { Estabelece as normas sobre as pesquisas prévias de endereço das } \\
\text { atividades econômicas/ocupações que serão desempenhadas e a } \\
\text { classificação de risco destas atividades econômicas/ocupações }\end{array}$ \\
\hline $\begin{array}{l}\text { Resolução CGSIM } \\
\text { No }^{\circ} 29 / 2012\end{array}$ & $\begin{array}{l}\text { Estabelece normas sobre o licenciamento das atividades econômicas } \\
\text { em relação ao Corpo de Bombeiros Militar. }\end{array}$ \\
\hline $\begin{array}{l}\text { Resolução CGSIM } \\
n^{\circ} 36 / 2016\end{array}$ & $\begin{array}{l}\text { Estabelece as normas a respeito do cancelamento do } \\
\text { Microempreendedor Individual inadimplente com o pagamento do } \\
\text { DAS-MEI e a DASN-SIMEI. }\end{array}$ \\
\hline $\begin{array}{l}\text { Resolução CGSIM } \\
\text { n 39/2017 }\end{array}$ & $\begin{array}{l}\text { Estabelece as normas a respeito do cancelamento do } \\
\text { Microempreendedor Individual inadimplente com o pagamento do } \\
\text { DAS-MEI e a DASN-SIMEI. }\end{array}$ \\
\hline $\begin{array}{l}\text { Resolução CGSIM } \\
\text { n }^{\circ} 43 / 2017\end{array}$ & Dispõe sobre alterações na resolução n 36 de 02 de maio de 2016. \\
\hline $\begin{array}{l}\text { Resolução CGSIM } \\
\text { n }^{\circ} 44 / 2018\end{array}$ & Dispõe sobre alterações na resolução n 36 . de 02 de maio de 2016. \\
\hline $\begin{array}{l}\text { Resolução CGSIM } \\
\text { n }^{\circ} 48 / 2018\end{array}$ & $\begin{array}{l}\text { Dispõe sobre o procedimento especial para o registro e legalização } \\
\text { do Microempreendedor Individual - MEI, por meio do Portal do } \\
\text { Empreendedor. }\end{array}$ \\
\hline $\begin{array}{l}\text { Resolução CGSN no } \\
140 / 2018\end{array}$ & $\begin{array}{l}\text { Dispõe sobre o Regime Especial Unificado de Arrecadação de } \\
\text { Tributos e Contribuições devidos pelas Microempresas e Empresas } \\
\text { de Pequeno Porte (Simples Nacional). }\end{array}$ \\
\hline $\begin{array}{l}\text { Resolução - RDC } \\
\text { 49/2013 - ANVISA }\end{array}$ & $\begin{array}{l}\text { Estabelece normas sobre a regularização do Microempreendedor } \\
\text { Individual - MEI em atividades econômicas/ocupações de interesse } \\
\text { da vigilância sanitária. }\end{array}$ \\
\hline $\begin{array}{l}\text { Resolução - RDC nº } \\
153 \text { - ANVISA }\end{array}$ & $\begin{array}{l}\text { Estabelece normas sobre a classificação de risco das atividades } \\
\text { econômicas de interesse da vigilância sanitária }\end{array}$ \\
\hline $\begin{array}{l}\text { Instrução Normativa } \\
\text { Mapa }{ }^{\circ} 16 / 2015\end{array}$ & $\begin{array}{l}\text { Estabelece normas de inspeção e fiscalização sanitária de produtos } \\
\text { de origem animal, referente às agroindústrias de pequeno porte }\end{array}$ \\
\hline
\end{tabular}

Fonte: elaboração própria (2019)

\section{CONSIDERAÇÕES FINAIS}

Este artigo apresentou brevemente as vantagens e desvantagens da lei do MEI. Os pontos aqui observados foram resultantes das análises de Cordeiro (2012) e Resende (2008) e da busca por informações diretas junto ao Portal do Empreendedor (2015), Brasil (2008) e Brasil (2011).

A seguir apresenta-se a síntese das principais vantagens que o programa do Microempreendedor individual oferece: isenções de taxas para o registro da empresa; redução da carga tributária; cobertura previdenciária; contratação de um funcionário com menor custo; ausência de burocracia e controle simplificado; acesso a serviços bancários (inclusive crédito); benefícios governamentais; compras e vendas em conjunto.

Como observado, o MEI apresenta muitas vantagens e inúmeros incentivos aos trabalhadores informais legalizarem seus empreendimentos, mas, no entanto, apresenta uma 
série de desvantagens que devem ser analisadas pelos optantes antes de tomar a decisão de optar pelo regime legal previsto na lei supracitada.

A seguir ilustram-se as principais desvantagens: restrições às determinadas atividades econômicas; não possui cobertura previdenciária plena; limitação no poder de contratação; necessidade de manter controle de receitas e despesas; dificuldades para pleitear a licença permanente do alvará de funcionamento; necessidade de contratação de um contador; e diversas causas que levam ao desenquadramento do MEI.

De um modo geral, este trabalho contatou que houve uma movimentação do estado brasileiro para disciplinar e garantir direitos isonômicos aos pequenos empreendimentos e que, este processo histórico e gradual, a pesar das limitações apresentadas, apresenta inúmeras vantagens cujos impactos atuam na esfera individual de cada empreendimento e na esfera social, ampliando a atuação do estado e promovendo o bem-estar da população.

\section{REFERÊNCIAS}

ACEMOGLU, D.; ROBINSON, J. Why Nations Fail: The Origins of Power, Prosperity, and Poverty. Crown Publishers: New York, 2012.

AMIN, M.; ISLAM, A. Are large informal firms more productive than the small informal firms? evidence from firm-level surveys in Africa. World Development. v.74, p.374-385, 2015.

BAUWENS, T.; LEMAÎTRE, A. Popular economy in Santiago de Chile: state of affairs and challenges. World Development.v.64, p.65-78, 2014.

BOYLE, E.The Rise of Reluctant Entrepreneurs.International Small Business Journal. v.12, n.2, p.63-69, 1994.

BRASIL. Lei Complementar $n^{\circ}$. 128/08, de 19 de dezembro de 2008. Altera a Lei Complementar 123, de 14 de dezembro de 2006, altera as Leis nos 8.212, de 24 de julho de 1991, 8.213, de 24 de julho de 1991, 10.406, de 10 de janeiro de 2002 - Código Civil, 8.029, de 12 de abril de 1990, e dá outras providências. Diário Oficial [da] República Federativa do Brasil, Poder Executivo, Brasília, DF, 22 dez. 2008.

Constituição. Constituição da República Federativa do Brasil: promulgada em 5 de outubro de 1988. Lex: legislação federal e marginalia, Brasília, 2013. Disponível em: 
<http://www.senado.gov.br/legislacao/const/con1988/CON1988_05.10.1988/CON1988.pdf>. Acesso em: 10 out.2014.

Decreto - lei $n^{\circ}$ 486, de 3 de março de 1969. Dispõe sobre escrituração e livros mercantis e dá outras providências. Diário Oficial [da] República Federativa do Brasil, Poder Executivo, Brasília, DF, Brasília, DF, 3 mar. 1969.

Lei complementar $n^{\circ}$. 123/06, de 14 de dezembro de 2006. Institui o Estatuto Nacional da Microempresa e da Empresa de Pequeno Porte e dá outras providências. Diário Oficial [da] República Federativa do Brasil, Poder Executivo, Brasília, DF, de 15 dez. 2006.

Lei $\mathrm{n}^{\circ}$ 10.406/ 2002. Institui o Código Civil. Diário Oficial [da] República Federativa do Brasil, Brasília, DF, 10 jan. 2002.

Lei $\mathrm{n}^{\circ}$ 9.317, de 05 de dezembro de 1996. Dispõe sobre o regime tributário das microempresas e das empresas de pequeno porte, institui o Sistema Integrado de Pagamento de Impostos e Contribuições das Microempresas e das Empresas de pequeno Porte SIMPLES e dá outras providências. Diário Oficial [da] República Federativa do Brasil, Brasília, 5 dez. 1996

. Lei $\mathrm{n}^{\circ}$. 139/2011, de 10 de novembro de 2011. Altera dispositivos da Lei Complementar 123, de 14 de dezembro de 2006, e dá outras providências. Diário Oficial [da] União, Poder Executivo, Brasília, DF, 11 nov. 2011.

Lei $n^{\circ}$. 8.212/91, de 24 de julho de 1991. Dispõe sobre a organização da Seguridade Social, institui Plano de Custeio, e dá outras providências. Diário Oficial [da] República Federativa do Brasil, Poder Executivo, Brasília, DF, 25 jul. 1991.

Lei $n^{\circ}$. 8.213/91, de 24 de julho de 1991. Dispõe sobre os Planos de Benefícios da Previdência Social e dá outras providências. Diário Oficial [da] República Federativa do Brasil, Poder Executivo, Brasília, DF, 25 jul. 1991.

CASTRO, J. O; KHAVUL, S.; BRUTON, G; D. Shades of Grey: How do Informal Firms Navigate Between Macro and Meso Institutional Environments? Strategic Entrepreneurship Journal.v.8, n.1, p.75-94, 2014.

CORDEIRO, F. R. S. As vantagens e desvantagens apresentadas aos micros empreendedores individuais com a promulgação da lei 128/2008. Trabalho de Conclusão de Curso (Graduação em Ciências Contábeis), Universidade Estadual da Paraíba. Campina Grande, 2012. 
CROSS, J. C. Entrepreneurship and Exploitation: Measuring Independence and Dependence in the Informal Economy. International Journal of Sociology andSocial Policy. v.17, n.3-4, p.37-63, 1997.

CUNNINGHAM, W. V.; MALONEY, W. Heterogeneity among Mexico's microenterprises: An application of factor and cluster analysis. Economic Development and Cultural Change.v.50, n.1, p.131-156, 2001.

DE MEL, S.; MCKENZIE, D.; WOODRUFF, C.The demand for, and consequences of, formalization among informal firms in Sri Lanka. American Economic Journal, 2013.

.Who are the microenterprise owners? Evidence from Sri Lanka on Tokman versus

De Soto. In: J. Lerner, J.; Schoar, A. (Eds.).International differences in entrepreneurship Chicago. University of Chicago Press, p. 63-87, 2010.

ELGIN, C. Informal economy in a dynamic political framework. Macroeconomic Dynamics.v.19, n.3, p.578-617, 2013.

ELGIN, C.; URAS, B. R. Is informality a barrier to financial development? SERIEs.v.4, n.3, p.309-331, 2013.

GALLIN, D. Propositions on Trade Unions and Informal Employment in Time of Globalization.Antipode. v.19, n.4, p.531-549, 2001.

GERXHANI, K.The Informal Sector in Developed and Less Developed Countries: A Literature Survey. Public Choice. v.120, n.2, p. 267-300, 2004.

GINDLING, T. H.; TERRELL, K. The effect of minimum wages on actual wages in formal and informal sectors in Costa Rica. World Development.v.33, n.11, p.1905-1921, 2005.

GRIMM, M.; KNORRINGA, P.; LAY, J. Constrained gazelles: high potentials in west Africa's informal economy. World Development.v.40, n.7, p.1352-1368, 2012.

LASTRES, H. M. M.; LEMOS, A. A. C. Políticas de apoio a pequenas empresas: do leito de Procusto à promoção de sistemas produtivos locais. In: Lastres, H. M. M.; Cassiolato, J. E.; Maciel, M. L. (Orgs). Pequena empresa: cooperação e desenvolvimento local. Relume Dumará Editora: Rio de Janeiro, 2003.

KUS, B. The informal road to markets: Neoliberal reforms, private entrepreneurship and the informal economy in turkey. International Journal of Social Economics.v.41, n.4, p.278293, 2014. 
LEE, C.; SHIH-CHANG, H. Institutional Entrepreneurship in the Informal Economy: China's Shan-Zhai Mobile Phones. Strategic Entrepreneurship Journal, v.8, n.1, p.16-36, 2014.

LEITE FILHO, F. T.; RAMOS, I. M. M.; RAMOS, R. R. (2012). O impacto do programa MEI para os Microempreendedores da cidade de Juazeiro do Norte. In: Encontro de Estudos sobre Empreendedorismo e Gestão de Pequenas Empresas, 2012, Goiânia. Anais..., p. 1-20. LIN, D.; LU, J.; LI, P. P.; LIU, X. Balancing formality and informality in business exchanges as a duality: A comparative case study of returnee and local entrepreneurs in china. Management and Organization Review, v.11, n.2, p.315-342, 2015.

LOAYZA, N.; RIGOLINI, J. Informal employment: Safety net or in economics no growth engine?. World Development, v.39, n.9, p.1503-1515, 2011.

LOUREIRO, P. R. A.; ARAUJO, R. A.; SOUZA, N. A. An evaluation of the Brazilian informal labor market from 1995 to 2008. Journal of Economic Studies, v.40, n.1, p.71-87, 2013.

MALONEY, W. F. Informality revisited. World Development, v.32, n.7, p.1159-1178, 2004.

MEAD, D. C.; MORRISSON, C. The informal sector elephant. World Development, v.24, n.10, p.1611-1619, 1996.

NARETTO, N., BOTELHO, M.; MENDONÇA, M. A trajetória das políticas públicas para pequenas e médias empresas no Brasil: do apoio individual ao apoio a empresas articuladas em arranjos produtivos locais. IPEA - Planejamento e Políticas Públicas, 27, 2014.

OLIVEIRA, J. Análise do enquadramento no MEI: um estudo de caso no comércio de cachorro quente em Florianópolis. Trabalho de Conclusão de Curso (Bacharel em Ciências Contábeis), Centro Sócio Econômico, Universidade Federal de Santa Catarina, Florianópolis, 2012.

ORSI, R.; RAGGI, D.; TURINO, F. Size, trend, and policy implications of the underground economy. Review of Economic Dynamics, v.17, n.3, p.417-436, 2014.

PORTAL DO EMPREENDEDOR. Estatísticas. Brasília, 2016. Disponível em: <http://www.portaldoempreendedor.gov.br/estatistica>. Acesso em: 19 maio. 2016.

RAND, J.; TORM, N. The benefits of formalization: Evidence from Vietnamese manufacturing SMEs. World Development, v.40, n.5, p.983-998, 2012.

RESENDE, V. Mais benefícios para as Micro e Pequenas Empresas. Revista Fenacon em Serviços, n.130, p.20-25, 2008. 
SARFATI, G. Estágios de desenvolvimento econômico e políticas públicas de empreendedorismo e de micro, pequenas e médias empresas (MPMEs) em perspectiva comparada: os casos do Brasil, do Canadá, do Chile, da Irlanda e da Itália. Rev. Adm. Pública, Rio de Janeiro, v.47, n.1, p.25-48, 2013.

SASSEN, S.Informalisation in Advanced Market Economies. Geneva: ILO, 1997.

SINGH, G.; DENOBLE, A. Early Retirees as the Next Generation of Entrepreneurs. Entrepreneurship Theory and Practice, v. 27, n.3, p.207-226, 2003.

SOUZA, C. Estado da Arte da Pesquisa em Políticas Públicas. In: HOCHMAN, G; ARretche, M.; MARQueS, E. (Org.). Políticas Públicas no Brasil. Rio de Janeiro: Editora Fio Cruz, 2007, p.65-86.

UZO, U.; JOHANNA MAIR, J. Source and Patterns of Organizational Defiance of Formal Institutions: Insights from Nollywood, the Nigerian Movie Industry. Strategic Entrepreneurship Journal, v.8, n.1, p.56-74, 2014.

WEBB, J. W.; IRELAND, R. D.; KETCHEN, D. J. Toward a greater understanding of entrepreneurship and strategy in the informal economy. Strategic Entrepreneurship Journal, v.8, n.1, p.1-15, 2014.

WEBB, J. W.; TIHANYI, R. D. L.; IRELAND, AND D. G. SIRMON.You Say Illegal, I Say Legitimate: Entrepreneurship in the Informal Economy.Academy of ManagementReview,v.34, n.3, p.492-510, 2009.

WEBB, J. W.; BRUTON, G. D.; TIHANYI, L.; IRELAND, R. D. Research on entrepreneurship in the informal economy: Framing a research agenda. Journal of Business Venturing, v.28, n.5, p.598-614, 2013.

WILLIAMS, C. C.; NADIN, S. Tackling the hidden enterprise culture: Government policies to support the formalization of informal entrepreneurship. Entrepreneurship and Regional Development, v.24, n.9-10, p.895-915, 2012. 